\title{
Research on Active Pressurized Forced Lubrication Deep Drawing Process and Evaluation of Lubrication Effect
}

\section{Duan Chen}

Yanshan University

Changcai Zhao ( $\nabla$ zhao1964@ysu.edu.cn )

Yanshan University

\section{Xiaoyi Chen}

Yanshan University

Haoyang Li

Yanshan University

Xin Zhang

Yanshan University

\section{Research Article}

Keywords: Forced lubrication, Hydraulic, Deep drawing, Friction, Comparative test

Posted Date: October 26th, 2021

DOI: https://doi.org/10.21203/rs.3.rs-1007805/v1

License: (9) This work is licensed under a Creative Commons Attribution 4.0 International License. Read Full License

Version of Record: A version of this preprint was published at The International Journal of Advanced Manufacturing Technology on February 14th, 2022. See the published version at https://doi.org/10.1007/s00170-022-08892-z. 


\section{Research on active pressurized forced lubrication deep drawing process and evaluation of lubrication effect}

\section{Duan Chen ${ }^{1,2} \cdot$ Changcai Zhao ${ }^{1,2} \cdot$ Xiaoyi Chen ${ }^{1,2} \cdot$ Haoyang Li ${ }^{1,2} \cdot$ Xin Zhang $^{1,2}$}

\section{Abstract}

Friction and lubrication are important parameters that affect the quality of sheet metal forming, excellent lubrication condition and less harmful friction can reduce local thinning of sheet metal, delay fracture and improve surface quality. Aiming at the poor friction conditions and difficult lubrication in the flange area during deep drawing, an active pressurized forced lubrication deep drawing(FLDD) process was proposed in this paper. A hydraulic system was employed to flush high pressure lubricating oil into the contact gap between die and sheet in the flange area. The high pressure hydrostatic oil film in the contact gap can reduce the real contact area and improve the lubrication condition effectively. The equipment is simple, the cost is low, and lubricating oil pressure can be measured and controlled. Under the conditions of $20 \mathrm{kN}, 35 \mathrm{kN}$ and $50 \mathrm{kN}$ blank holder force(BHF), FLDD test of box parts was carried out with $5 \mathrm{MPa}$ and $9 \mathrm{MPa}$ pressure water-based lubricating oil. The horizontal comparison experiment was conducted with common lubricating media such as polyethylene film(PE film), high-purity molybdenum disulfide particles, vegetable oil and water-based lubricating oil under the same process conditions. Lubrication effect was evaluated by obtaining test data. Test results illustrated that the lubrication effect of high-purity molybdenum disulfide particles was the best and that of vegetable oil was the worst. The lubrication effect of water-based mineral lubricant was significantly improved after pressurization. The maximum forming height was increased by $17.97 \%$, the maximum forming force was reduced by $8.9 \%$, the maximum wall thickness thinning rate was reduced by $7 \%$, and the lubrication effect of $9 \mathrm{MPa}$ pressure was superior to that of $5 \mathrm{MPa}$. Although there is still a certain

\footnotetext{
Changcai Zhao

zhao1964@ysu.edu.cn

${ }^{1}$ Key Laboratory of Advanced Forging \& Stamping Technology and Science (Yanshan University), Ministry of Education of China, Qinhuangdao 066004, Hebei, China

${ }^{2}$ College of Mechanical Engineering, Yanshan University, Qinhuangdao 066004, Hebei, China
} 
shortfall with special lubricating media such as high-purity molybdenum disulfide, FLDD process has definite application value in improving production environment, pollution control and automatic production.

Key words Forced lubrication · Hydraulic - Deep drawing · Friction · Comparative test

\section{Introduction}

Friction and lubrication are unavoidable topics in sheet metal forming. Good lubrication condition has the advantages of reducing forming force, improving forming limit, reducing wall thickness thinning rate, improving surface quality of formed parts, reducing mold wear, etc. Improving lubrication conditions to reduce the coefficient of friction is of great importance to the forming process [1-3]. In recent years, scholars at home and abroad have conducted a lot of theoretical research and practical exploration on antifriction measures and lubrication technology in sheet metal forming. Most of them are mainly focused on development of new lubricating media, self-lubricating material molds, coatings or textures and hydrodynamic lubrication processes.

Several scholars have found that the addition of solid particles to oil-based lubricants could significantly improve extreme pressure performance of lubricant, reduce the contact effect between metals and improve lubrication conditions. Uda et al [4] developed lubricants with different solid ingredients, and found that the lubricant with mica powder had better friction performance through friction tests, its lubrication superiority was verified in hot stamping of 22MnB5 steel. Tan et al [5-6] investigated the extreme pressure performance of lubricants with different mass fraction of $\mathrm{SiO}_{2}$ nanoparticles by utilizing deep drawing process with increased BHF, and observed that surface quality of formed parts was smoother when the mass fraction of nanoparticles was $2 \%$, and drawing ratio was also improved. Additionally, it was discovered that the addition of $\mathrm{SiO}_{2}$ nanoparticles was beneficial in delaying fracture during the deep drawing of SUS304 cylinder parts. Diabb et al [7] added 0.0125-0.1\% mass fraction of $\mathrm{SiO}_{2}$ nanoparticles into sunflower seed oil and corn oil as mixed 
lubricant and applied it to single point progressive forming. The effects of enhanced lubricants on friction and roughness during single-point forming of aluminum alloys were analyzed using the Stribeck Curve, while the interaction between nanoparticles and vegetable oils was investigated using Fourier transform infrared spectroscopy. Kamali et al [8] performed a comparative test using three lubrication conditions of dry friction, mineral oil lubrication, and addition of $\mathrm{TiO}_{2}$ nanoparticle lubricant in micro-drawing deep forming of magnesium-lithium alloy, and the results indicated that forming force was reduced by $14.14 \%$ and surface roughness Ra of formed part was reduced by $18.18 \%$ after the addition of $\mathrm{TiO}_{2}$ nanoparticles.

Furthermore, in order to reduce the forming friction coefficient, a number of researchers have paid more attention to mold materials and surface treatment. In miniaturization and ultra-precision parts forming, Diamond-like carbon(DLC) film is attracting more and more attention due to its lower friction coefficient and high wear resistance [9-11]. Wang et al [12] deposited functional gradient multilayer DLC films on mold surface employing plasma injection method and conducted experimental investigations on the films adopting atomic force microscopy, raman spectroscopy, nanoindentation test and ball-disk friction test to verify their low friction coefficient and high wear resistance. Micro-parts with high surface quality and uniform thickness distribution were yielded during micro-drawing tests utilizing surface-modified mold. Sulaiman et al [13] investigated the effect of DLC/TiAIN coating on mold surface under unlubricated and oil-lubricated conditions through experimental and numerical analysis, experimental results demonstrated that DLC/TiAIN coating was effective in reducing the friction coefficient and forming force under both dry and oil-lubricated conditions. In addition, some scholars were concerned about micro-textures and pits on die surface, those were employed to store and adsorb lubricant to achieve micro-hydrodynamic lubrication effect and improve lubrication conditions. Chen et al [14-15] used laser machining technology (LST) to manufacture triangular texture with edge length of $500 \mu \mathrm{m}$ at the flange area, it was verified that surface texture had a positive effect on reducing the contact friction coefficient and improved the forming quality through deep drawing tests and numerical analysis. Taha-Tijerina et al [16] 
explored the influence of surface texture LST process parameters on friction and wear via friction wear experiments, technical parameters applicable to sheet deep drawing were optimized, such as texture texturized area ratio, texture shape and size. Nevertheless, considering the scope of coating film processing and cost factors, few applications in large-scale industrial production have been reported. At present, it is mostly applied in the forming of micro parts.

Regarding the sheet drawing process itself, research scholars and engineers have also explored a number of lubrication options. During hydrodynamic deep drawing, as the punch descends, the liquid in the cavity of die is pressurized and the pressure increases continuously. When the pressure reaches a certain value, it will overflow from the gap between the sheet metal and die, then hydrodynamic lubrication appears [17]. Takayuki et al. [18] investigated the liquid outflow characteristics in the forming process by directly measuring the overflow liquid pressure distribution in the flange area and integrating it, explained that the influence of fluid lubrication on sheet metal varies with different deformation stages during deep drawing. Abbadeni et al [19] illustrated the lubrication mechanism of the contact zone at flange area during hydrodynamic drawing process, proposed an analytical model of the non-uniform fluid pressure distribution and the flow characteristics of the overflow lubricant film in the die cavity by means of the Reynolds equation, and the effects of BHF and fluid pressure on formability was investigated through AA5086 aluminum alloy drawing tests. Horikoshi et al [20] presented a scheme for the deep drawing process utilizing localized high-pressure water lubrication, high-pressure water stream which ejected through small holes machined on the die to lubricate the frictional interface. Flow characteristics parameters of liquid was calculated by Reynolds equation, and the interaction between nozzle position, number and plate deformation were analyzed by combining computational fluid dynamics and finite element method. Finally, the superiority of this scheme was verified by a series of tests. Yang [21-22] put forward a lubrication scheme employing the relative motion of die to generate hydrodynamic pressure, and used mean Reynolds equation to propose a friction model related to oil film thickness, surface roughness, oil viscosity, interfacial pressure, sliding velocity 
and strain rate. Contact area ratio, friction coefficient and strain distribution were predicted combining with finite element simulation during deep drawing.

In sheet metal deep drawing, due to large contact stress and wrinkles caused by deformation, the lubricating medium applied on sheet surface is easy to be squeezed away, and the lubricating oil film is likely to be cut off, resulting in lubrication failure at final. The FLDD process proposed in this paper is an active lubrication process with controllable pressure, which promotes the integrity of lubricating oil film by actively pressurizing lubricating oil. Under complex and changeable contact condition in sheet forming, high pressure lubricant with controlled pressure was utilizing to improve friction conditions and increase effective lubrication area. Under the same condition of process parameters and blank size, horizontal comparison tests were conducted between FLDD process and common deep drawing process using PE film, molybdenum disulfide, vegetable oil, water-based lubricating oil. The feasibility and superiority of FLDD process were verified by exploring the forming height, forming force, and wall thickness distribution.

\section{Technology principle}

According to the principle of plasticity mechanics, tangential compressive stress of flange area sheet increases as that continuously flows into the fillet of die during deep drawing, when BHF provided by blank holder is not enough to resist the bending deformation of the sheet caused by tangential compressive stress, wrinkling occurs. The hydrodynamic lubricating oil film produced by plate flow is easy to be crushed by the folds caused by plate instability, resulting in lubrication failure. Increased BHF is usually adopted to prevent wrinkling, but larger BHF tends to make the lubricating oil difficult to be saved in the contact gap, lubricating oil is squeezed away, and lubricating oil film cannot be formed. Poor lubrication condition increases the forming force, resulting in the fracture of sheet, which has a great adverse impact on the plate forming. 


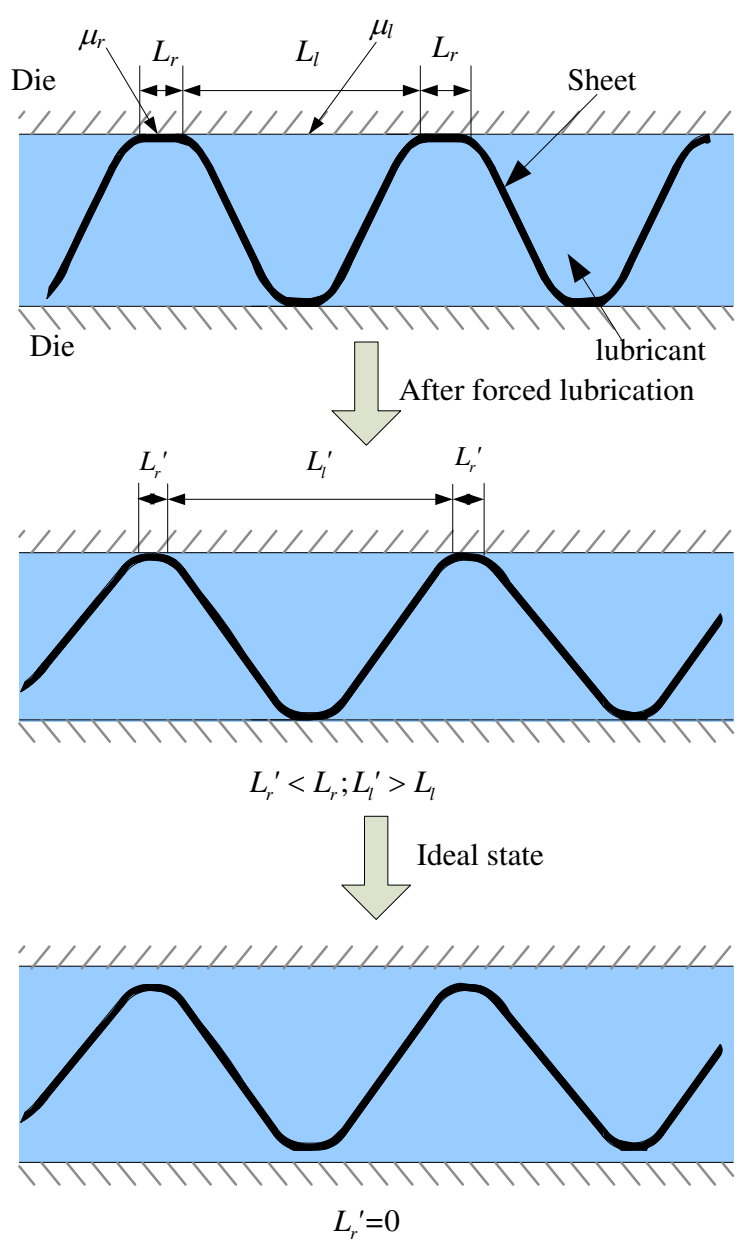

Fig. 1 Schematic diagram of contact between plate and die after wrinkling

Fig. 1 illustrates the schematic diagram of contact relationship after wrinkling in the flange area during deep drawing. Assuming that the friction coefficient between sheet and die is $\mu_{r}$, the friction coefficient between sheet and lubricant is $\mu_{l}$, the friction coefficient in the flange area can be expressed by Eq. (1).

$$
\mu=\alpha \mu_{r}+(1-\alpha) \mu_{l}
$$

Where $\alpha$ is the true contact area ratio, $\alpha=L_{r} /\left(L_{r}+L_{l}\right)$.

In traditional deep drawing process, due to large contact stress and constant changes in contact surface, hydrodynamic lubrication generated by the relative motion is easily destroyed. In particular, with the increase of the drawing ratio, the tangential compressive stress in the flange area is getting larger and larger, wrinkling is more and more serious, and wrinkling peak is likely to lead to the loss of lubricant under larger BHF, resulting in a larger value of $\alpha$ and increased friction. 
In PLDD process mentioned in this article, a hydraulic oil source is employed to actively inject high-pressure lubricant into the contact gap between sheet metal and die. The lubricating oil film fills the contact gap by controllable pressure, with a view to forming a stable hydrostatic oil film under the condition of high contact pressure. After lubricating oil film reaches a certain pressure, it invades the contact gap between wrinkle peak and die, bears part of BHF, which has an obvious effect on relieving the cutting and crushing of lubricating oil by large BHF and deformation, reducing the value of $\alpha$ and increasing the effective lubrication area of friction surface. Ideally, the value of $\alpha$ can be infinitely close to 0 , and BHF will be borne entirely by the oil pressure, but this is difficult to achieve in practice. The oil supply system has complete oil inlet and return piping, valve control and oil pressure monitoring system, oil pressure can be measured and controlled in real time, which can realize the working conditions of circulating oil supply, holding pressure oil supply and variable pressure oil supply with the plastic deformation process. The process principle is shown in Fig. 2.

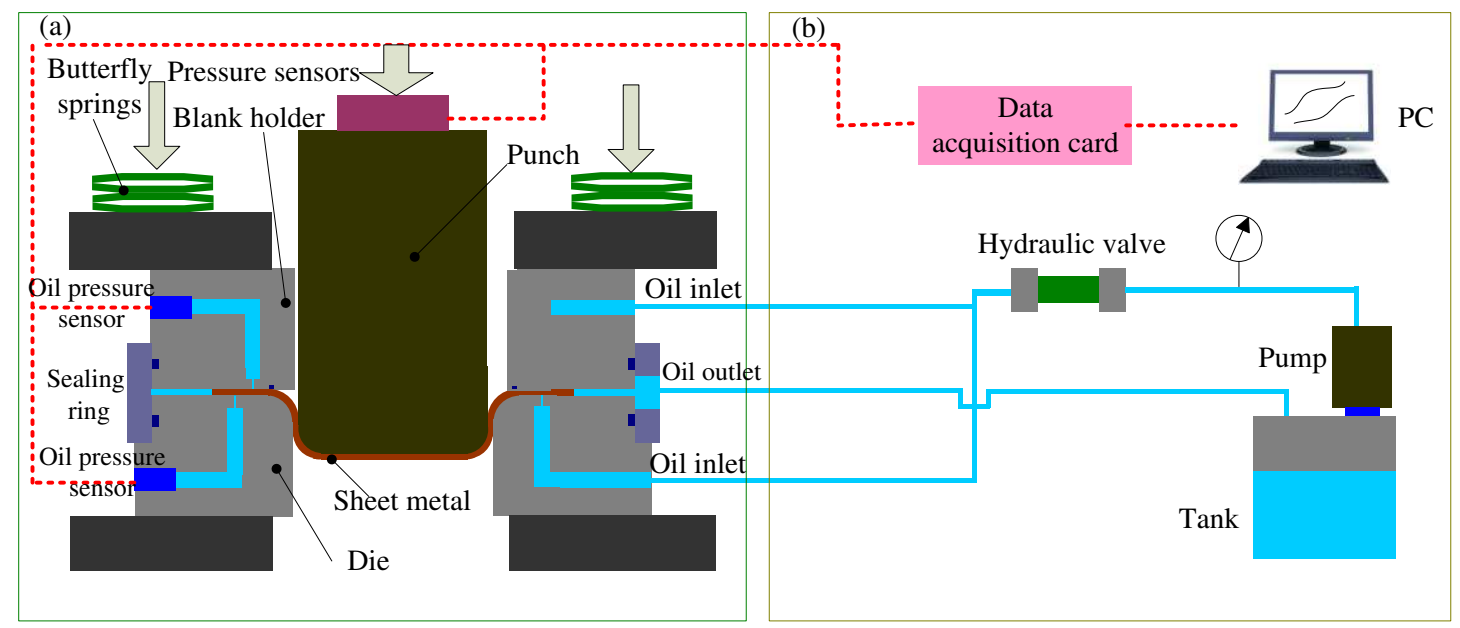

Fig. 2 Schematic diagram of FLDD process (a) Schematic diagram of die (b) Oil supply system

The contact gap between sheet and die forms the oil cavity, and O-rings are installed on the mating surface of die and sealing ring to ensure that the oil cavity is closed. In the initial stage of deep drawing, firstly, the punch presses down $2 \mathrm{~mm}$ to make sheet bend and deform at the fillet of die and close to the fillet to achieve the purpose of natural sealing. Then open reversing valve to supply oil, when the pressure sensor monitors that the oil pressure in the oil chamber reaches the planned pressure, 
the punch continues to press down until the deep drawing is completed. During the whole drawing process, parameters such as oil pressure, forming force and punch stroke can be displayed in real time through data acquisition card and can be adjusted online. Compared with hydrodynamic deep drawing process mentioned in the references in the previous section, the process equipment proposed in this paper is simple, easy to operate and low cost.

\section{Process test}

\subsection{Material}

SPCC cold rolled steel plate with thickness of $0.8 \mathrm{~mm}$ was selected for the deep drawing test. SPCC is a kind of carbon steel cold rolled sheet, which is widely used in automobile manufacturing, household appliances, instruments, food packaging and other fields, its chemical composition is shown in Table 1. The uniaxial tensile specimens shown in Fig. 3(b) were designed, and Inspekt Table 100KN electronic universal material testing machine was adopted to perform the uniaxial tensile specimens at a strain rate of $0.004 \mathrm{~s}^{-1}$ for three directions of $0^{\circ}, 45^{\circ}$ and $90^{\circ}$ from rolling direction, and the real stress and strain curves of the material were calculated by Eq. (2) and Eq. (3), as shown in Fig. 1(c). Elastic modulus $E$ was obtained by fitting the elastic section of the stress-strain curve using Eq. (4), and the mechanical parameters such as strength coefficient $K$ and hardening index $n$ were obtained by fitting the plastic phase of the real stress-strain curve utilizing the Swift model (Eq. (5)), whose basic mechanical properties are shown in Table 2.

Table 1 Chemical composition of SPCC (wt, \%)

\begin{tabular}{cccccc}
\hline & $\mathrm{C}$ & $\mathrm{Mn}$ & $\mathrm{P}$ & $\mathrm{S}$ & $\mathrm{AL}$ \\
\hline SPCC & 0.12 & 0.6 & 0.04 & 0.04 & 0.02 \\
\hline
\end{tabular}



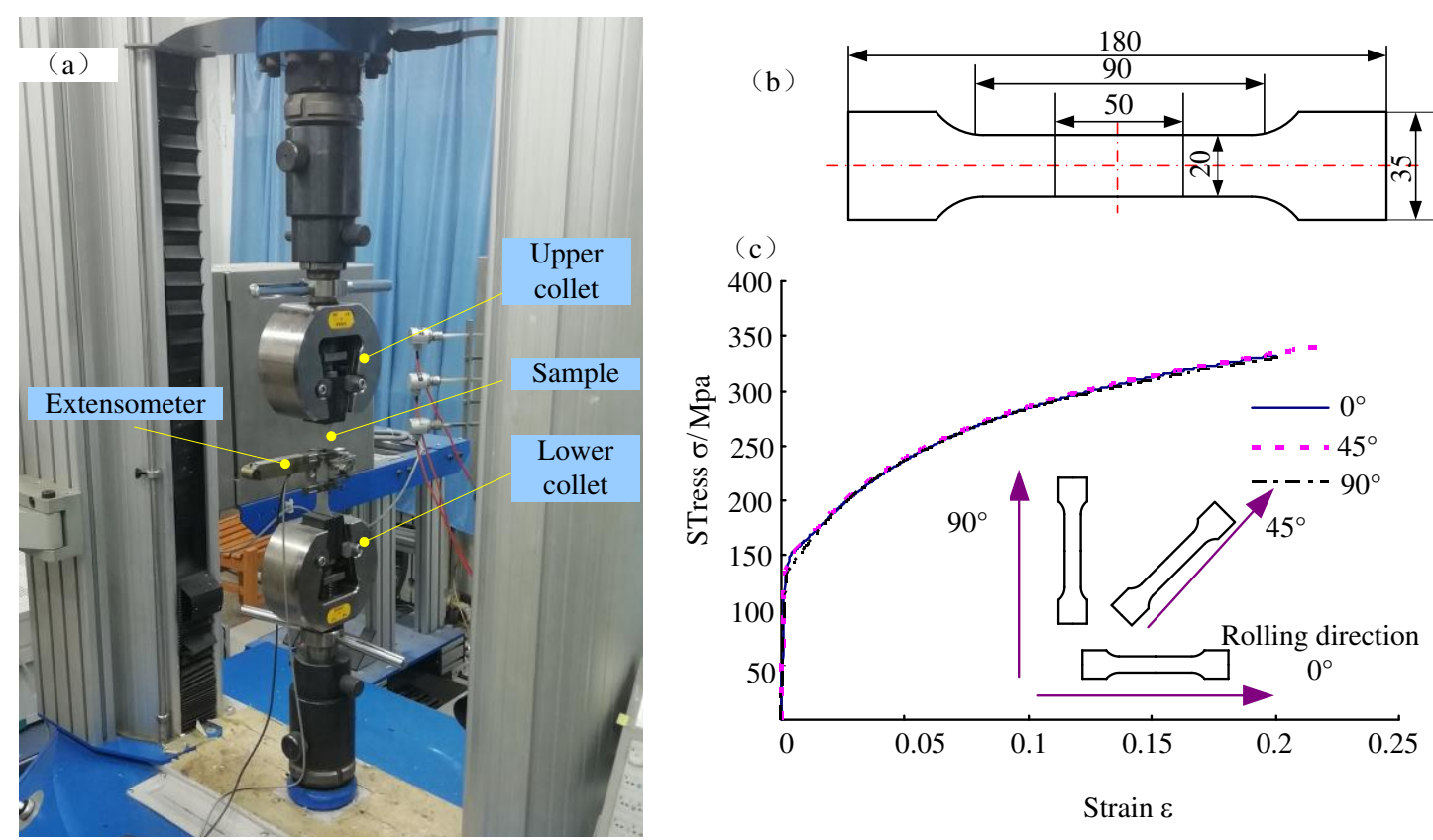

Fig. 3 Uniaxial tensile test a) Test equipment b) Sample size c) True stress-strain curves

$$
\begin{gathered}
\sigma=F \cdot L / A_{0} \cdot L_{0} \\
\varepsilon=\ln \left(1+\Delta L / L_{0}\right)
\end{gathered}
$$

Where, $\sigma, \varepsilon$ are true stress and strain; $F$ is tensile force; $L$ is the gauge length; $L_{0}$ is the initial gauge length (initial length $L_{0}=50 \mathrm{~mm}$ ); $\Delta L$ is the gauge elongation.

$$
\begin{gathered}
\sigma=E \varepsilon_{e} \\
\sigma=K\left(\varepsilon_{P}+\varepsilon_{0}\right)^{n}
\end{gathered}
$$

Where $E$ is the elastic modulus $(\mathrm{MPa}) ; \varepsilon_{e}$ is elastic strain; $\varepsilon_{p}$ is plastic strain; $\varepsilon_{0}$ is strain value of the material at yield; $K$ is strength coefficient (MPa); $n$ is hardening index.

Table 2 Mechanical property parameters of SPCC

\begin{tabular}{cccc}
\hline Elastic modulus & Yield stress & $K$ & $n$ \\
\hline $219 \mathrm{GPa}$ & $152 \mathrm{MPa}$ & $495.7 \mathrm{MPa}$ & 0.2444 \\
\hline
\end{tabular}

\subsection{Die design}

According to the process requirements, the FLDD process experiment die for box-shaped parts was designed. The three-dimensional schematic diagram and detailed dimensions of die are shown in Fig. 4. The set of die is mainly composed of punch, blank holder, concave die, sealing device and assembly base. Compared with 
traditional deep drawing process, the oil supply pipeline and sealing device are added. BHF Control was adopted in deep drawing process, equipped with displacement sensor, punch pressure sensor and oil pressure sensor. The process parameters such as punch displacement, forming force and oil cavity pressure were monitored in real time.

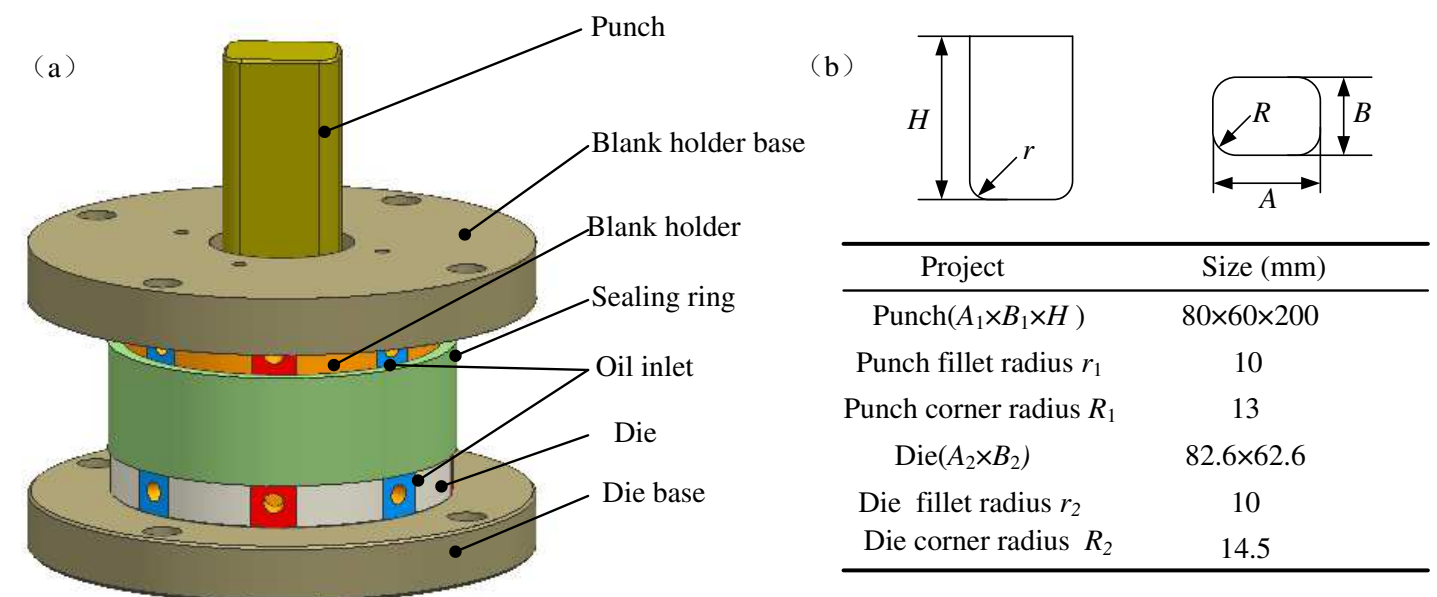

Fig. 4 Test die and size

During the drawing process, the plate was lubricated on both sides, and the flange area of concave die and blank holder were opened with oil holes, which were symmetrically distributed. In Fig. 4, O-ring groove was machined on the mating surface of sealing ring and die, and O-ring seal was adopted. As shown in Fig. 5, in order to distribute the lubricating fluid quickly and evenly on the surface of die and improve the lubrication effect, a total of 8 oil supply ports were manufactured at straight edge area and rounded corner area of die flange zone, while hydraulic valves were utilized to control the synchronized oil supply. No. 9 oil hole was a pressure measuring hole, which could monitor the pressure of oil film on contact surface in real time. In consideration of preventing the oil holes from adversely affecting sheet deformation, the diameter of oil holes was less than $2 \mathrm{~mm}$. 


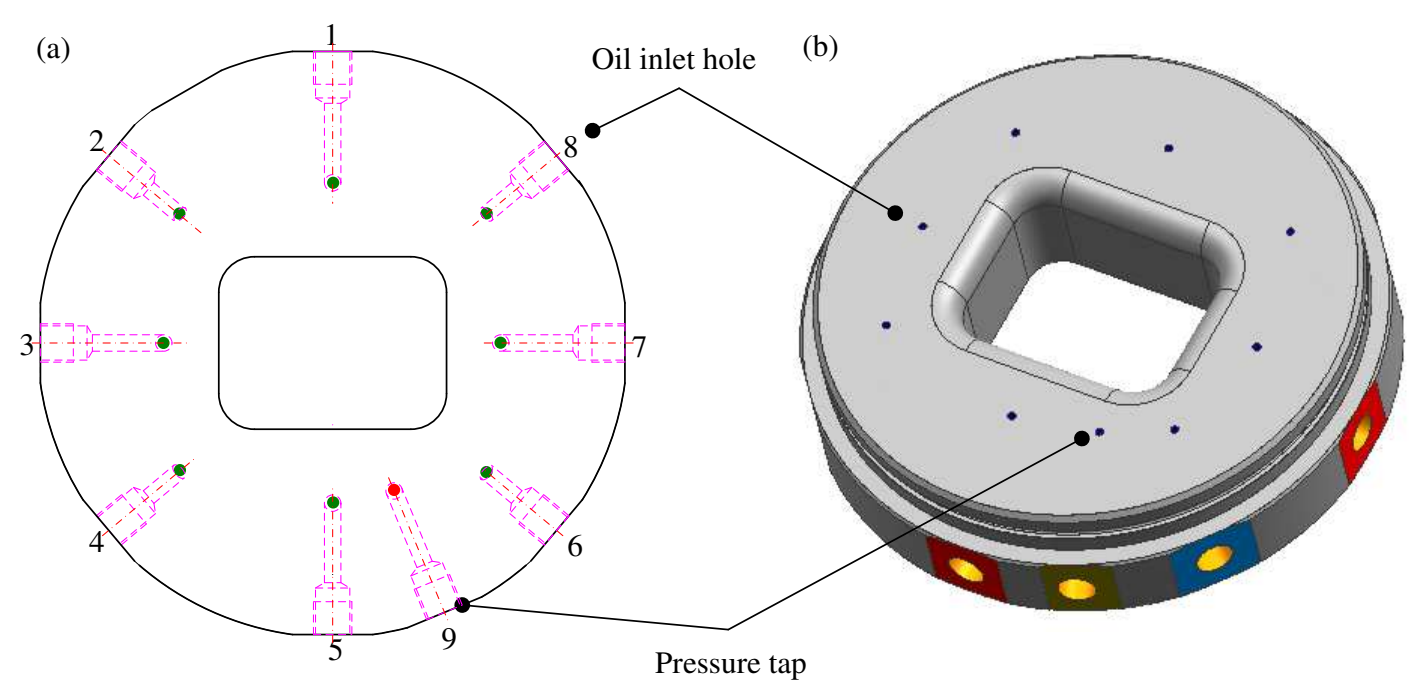

Fig. 5 Schematic diagram of working surface of die

\subsection{Experimental process}

The test material of $0.8 \mathrm{~mm}$ SPCC cold rolled sheet was selected for deep drawing test which was carried out on the 500T hydraulic press in laboratory, and the drawing speed was set to $30 \mathrm{~mm} / \mathrm{min}$. Forming force was output by the pressure sensor of hydraulic press, displacement was measured by the pull rope displacement sensor fixed on the moving beam of hydraulic press, the displacement, force, and oil pressure were transmitted from data acquisition card to the computer for real-time acquisition during forming process. BHF was provided by 3-6 groups of A71 or A100 type butterfly springs during deep drawing process. Butterfly springs were calibrated for spring stiffness by compression test and deformed at $75 \%$ of the maximum compression to prevent spring damage. Accurate BHF was obtained by accurately measuring the spring compression. Water-based mineral lubricating oil was chosen as the lubricating medium. A small hydraulic station with a rated power of $2.2 \mathrm{kw}$ maximum output pressure of $20 \mathrm{MPa}$ oil supply was adopted as the supply system, hydraulic station integrated reversing valve, relief valve, pressure gauge and other components to control the flow of oil, the maximum flow rate of $4.7 \mathrm{~L} / \mathrm{min}$. 


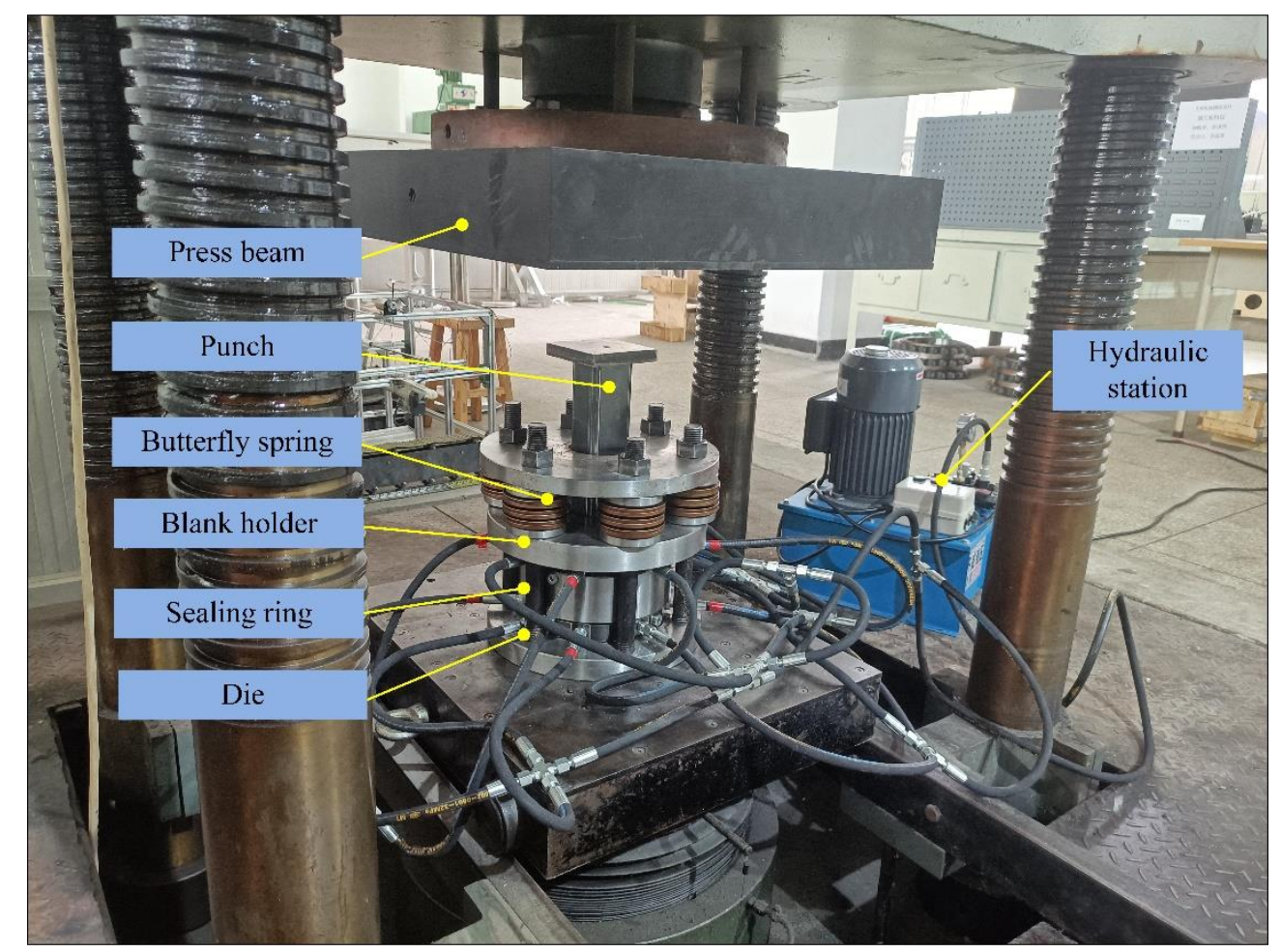

Fig. 6 Test equipment

The shape of test blank is shown in Fig. 7. The value range of BHF was taken according to the Eq. (6) proposed by Fukui and Yoshida [23] to calculate the minimum unit BHF. Yet, Yoshida's formula to calculate the unit BHF was based on cylindrical parts, the shape in this paper was box-shaped parts, so $R_{0}$ and $r_{2}$ in Eq. (6) were estimated by adopting the equivalence radius $R_{\text {equ }}$ and $r_{\text {equ }}$ of Eqs. (7-8) [24].

$$
p=\frac{\left(\sigma_{s}+\sigma_{b}\right) R_{0}\left[\frac{2\left(R_{0}-r_{2}-r_{d}\right)}{t}-8\right]}{90 \pi\left[R_{0}^{2}-\left(r_{2}+r_{d}\right)^{2}\right]} \mathrm{MPa}
$$

Where $p$ is the unit BHF; $\sigma_{s}$ is the yield stress; $\sigma_{b}$ is the tensile strength; $R_{0}$ is the blank radius; $r_{2}$ is the radius of the drawing cylinder; $t$ is the sheet thickness; $r_{d}$ is the fillet radius of die.

$$
R_{e q u}=\sqrt{S / \pi}
$$

Where $R_{\text {equ }}$ is the equivalence radius of blank; $S$ is the blank area.

$$
r_{\text {equ }}=\sqrt{A B / \pi}
$$

Where $r_{\text {equ }}$ is the equivalence radius of formed parts; $A$ is the long side of box; $B$ is the short side of box. 


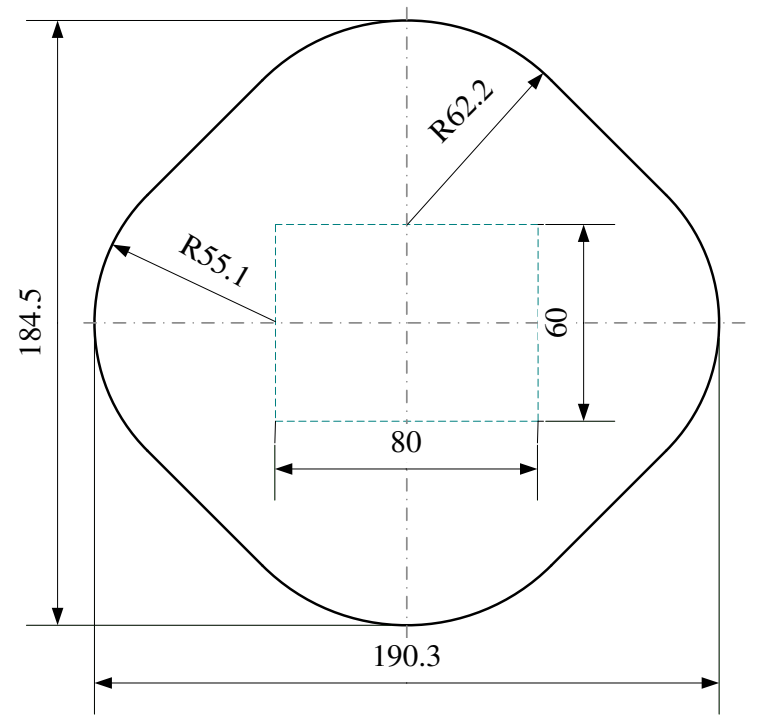

Fig. 7 The shape of test blank (mm)

In traditional deep drawing process, the pressure of butterfly spring is the corresponding BHF. In the process of FLDD, the high-pressure lubricating oil will give an upward reaction force to the blank holder, so the actual BHF can be expressed by Eq. (9).

$$
Q=F_{s}-p_{l} S_{Q}
$$

Where: $Q$ is the actual BHF; $F_{s}$ is butterfly spring pressure; $p_{l}$ is lubricating oil pressure; $S_{Q}$ is the effective area of blank holder.

In order to qualitatively and quantitatively evaluate FLDD process, four commonly used lubricating media such as PE film, molybdenum disulfide, vegetable oil and water-based mineral lubricating oil were adopted for horizontal comparison test with FLDD process under the pressure of 5MPa and 9MPa(5MPa-FLDD, 9MPa-FLDD). All lubricating media were evenly applied on the upper and lower surfaces of the plate, the lubricant name and number are shown in Table 3 . The same water-based mineral lubricating oil of lub D was used for FLDD.

Table 3 Lubricant name and number

\begin{tabular}{ccccccc}
\hline Number & Lub A & Lub B & Lub C & Lub D & Lub E & Lub F \\
\hline \multirow{2}{*}{ Name } & PE film & Molybde & vegetable & water-based mineral & 5MPa- & 9MPa- \\
& & -num & oil & lubricating oil & FLDD & FLDD \\
\hline
\end{tabular}

2.4 Evaluation index of lubrication effect 
In the production of sheet metal deep drawing, harmful friction is mainly concentrated in the flange area, and the lubrication effect in this area has a great impact on the formability and quality. In this paper, in order to qualitatively and quantitatively evaluate the lubrication effect under different lubrication conditions, box-shaped drawing test of $0.8 \mathrm{~mm}$ thick SPCC plate was carried out, and the evaluation was implemented through the following indexes:

(1) Maximum drawing height: under the same BHF conditions, the height of the formed parts under different lubrication conditions was measured. Taking no fracture as the standard, the greater the height, the better the lubrication effect;

(2) Forming force: under the same BHF condition, the forming force curves under different lubrication conditions were compared and analyzed. The smaller the forming force, the better the lubrication effect ;

(3) Maximum thinning rate: under the same BHF, the formed parts with the same forming depth under different lubrication conditions were selected and cut by spark-erosion wire cutting, the thinning was measured. The smaller the maximum thinning rate, the better the lubrication effect.

\section{Results and discussion}

\subsection{Effect of lubrication conditions on sheet metal forming limit}

In the deep drawing of axisymmetric parts, the sheet forming ability is usually indicated by the limit ratio of drawing (LRD), whose value is the ratio of blank diameter to formed cylinder diameter. For the forming of box parts, due to its nonaxisymmetry, a unified standard for calculating the forming limit has not been formed, equivalent radius in Eqs. (7-8) were used to calculate equivalent drawing ratio of box parts by a number of scholars. In this paper, the most intuitive forming height was utilized to compare the forming capacity of sheet metal under different lubrication conditions. 


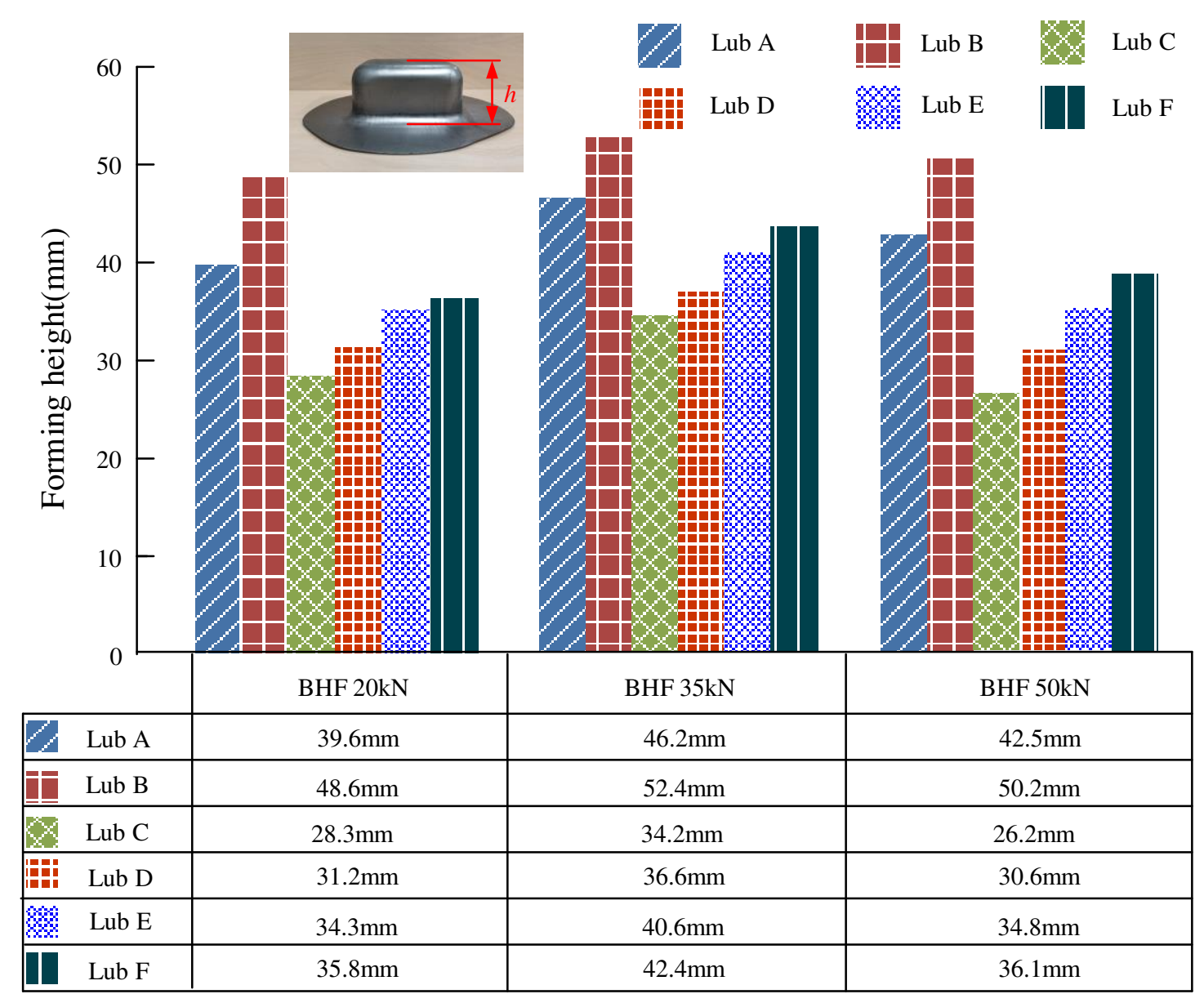

Fig. 8 Forming height under different process parameters

Under the conditions of $20 \mathrm{kN}, 35 \mathrm{kN}$ and $50 \mathrm{kN}$ BHF respectively, deep drawing test was conducted under the lubrication conditions A-F in Table 3. The forming height of box part at the moment of fracture is shown in Fig. 8. As can be seen in the figure, the best forming performance was achieved when BHF was $35 \mathrm{kN}$, because a small crimping force will cause wrinkling in the flange area and prevent the plastic flow of metal, while a large BHF will cause the metal in the flange area to be unable to flow to the center of die. The sheet coated with high purity molybdenum disulfide powder had the highest forming height regardless of BHF condition. This is mainly because the molybdenum disulfide powder was extruded into a bright lubricating coating under high contact pressure and attached to the surface of the sheet, the friction coefficient of lubricating layer was extremely small and it was not easy to fall off. The greater the contact pressure, the more obvious the advantage. Yet, it is difficult to apply molybdenum disulfide powder on a large scale in sheet forming lines 
because of the difficulty of quantitative uniformity control and the negative impact on the production environment. It can be seen from Fig. 8 that the water-based mineral lubricating oil improved forming height of metal sheet after pressurization, which is due to the fact that pressurized lubricating oil was more likely to retain and invade the contact gap between sheet and die under high contact pressure, increasing the proportion of fluid lubrication area and promoting metal flow. Under three BHF conditions, the forming height increased by $9.93 \%, 10.92 \%$, and $13.73 \%$ at a lubricant pressure of $5 \mathrm{MPa}$, and by $14.73 \%, 15.85 \%$, and $17.97 \%$ at a lubricant pressure of 9 $\mathrm{MPa}$, respectively. It is evident that forming height is higher than $5 \mathrm{MPa}$ at $9 \mathrm{MPa}$, which indicates that the increase in oil pressure is more conducive to the transformation from boundary lubrication to fluid lubrication at contact surface. It was also discovered that the higher the lubricant pressure, the greater the improvement in forming performance under relatively high BHF conditions, demonstrating that it was more difficult to form and maintain lubricant film under high BHF conditions, while higher oil pressure promoted the establishment of a lubricant film. During the test, it was observed that the PE film exhibited good lubricating properties, although the thinner film was easy to crush and the thicker film would affect the forming accuracy.

\subsection{Effect of lubrication conditions on forming force}

In the process of sheet metal forming, forming force is mainly composed of the force required for sheet metal plastic deformation and the force to overcome friction loss. Friction loss in deep drawing is mainly concentrated in the flange area, therefore, it is significant to reduce the friction coefficient in the flange area and improve its lubrication conditions to reduce the forming load and energy consumption. It is well known that good lubrication conditions can reduce the forming load under the same process conditions. Fig. 9 demonstrates the influence of different lubrication conditions on the trend of forming force at $20 \mathrm{kN}, 35 \mathrm{kN}$ and $50 \mathrm{kN}$ BHF respectively. 

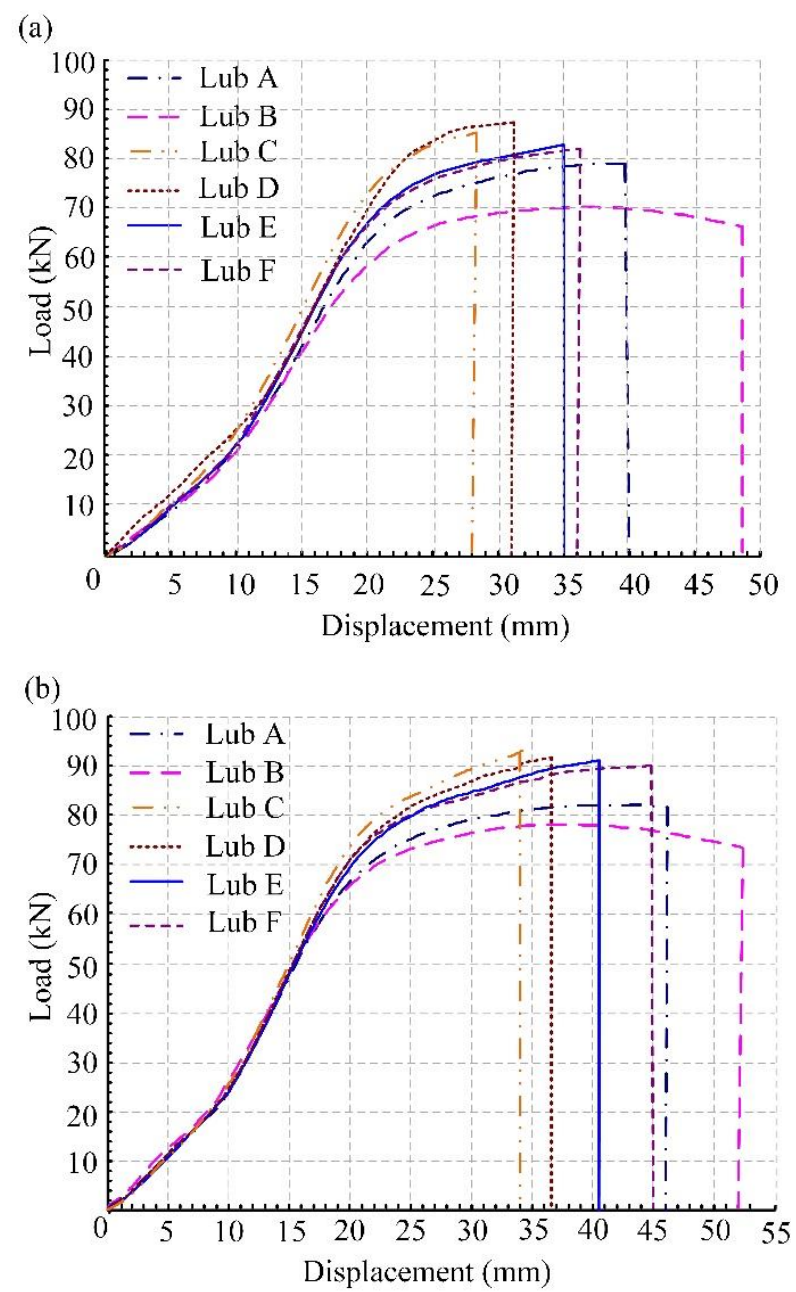

(c)

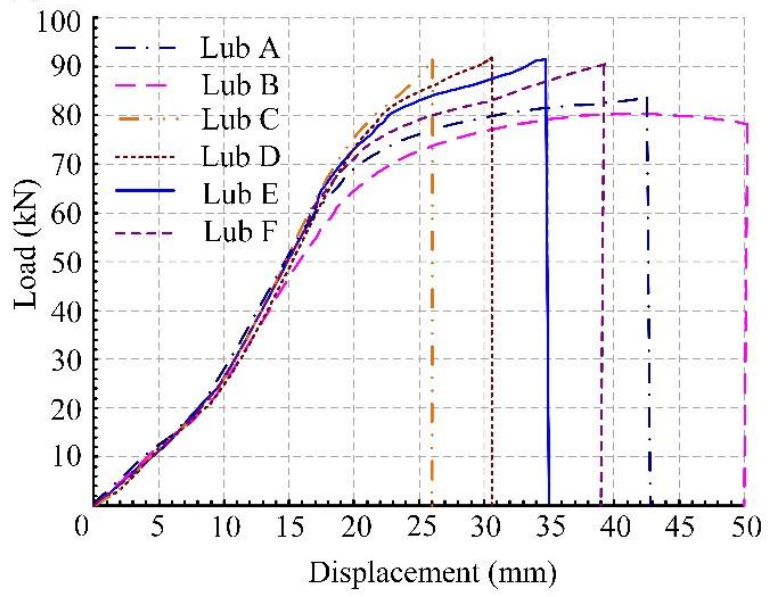

Fig. 9 Force-displacement curves (a) $\mathrm{BHF}=20 \mathrm{kN}$; (b) $\mathrm{BHF}=35 \mathrm{kN}$; (c) $\mathrm{BHF}=50 \mathrm{kN}$.

In the case of the same process parameters such as mold and blank shape, BHF, when the punch displacement is consistent, a smaller forming force indicates better lubrication condition, while on the contrary poor friction condition generally leads to a larger forming force. From the curve in Fig. 9, it can be observed that in the initial 
stage of deep drawing, the plate deformation in the flange area was small and the difference of different lubrication conditions on the forming force was not obvious. As the sheet metal in the flange area flowed into die, tangential compressive stress was greater and greater, wrinkling was more and more serious, and friction environment was worse and worse. The difference of forming force between different lubricating media began to become apparent. As mentioned in the previous section, high purity molybdenum disulfide was extruded into a shiny coating on sheet surface under high contact pressure, and the friction between die and sheet was converted into friction between die and molybdenum disulfide film, thus the forming force with molybdenum disulfide lubrication was minimal regardless of BHF conditions. In the process of deep drawing test in this article, drawing speed was slow and polyethylene film is less damaged, so the use of polyethylene film lubrication had also achieved good results in reducing the forming load. When vegetable oil lubrication was selected, forming force quickly reached the peak value and then fracture occured under three BHF conditions, which indicates the worst performance of vegetable oil in Table 3.

From Fig. 9, it can be seen that the maximum force under various lubricant conditions was around $90 \mathrm{kN}$, because this was the bearing limit of selected material under this geometric parameter, fracture occured when the load limit was exceeded. Therefore, it was unscientific to judge the lubrication performance only from the maximum force value. Lubricant D-F represented water-based mineral oil, 5MPa-FLDD and 9MPa-FLDD respectively. Pressurized lubricating oil played a positive role in reducing forming force, which was reflected by the force value at the same punch stroke moment. When punch stroke was unified at $30 \mathrm{~mm}$, forming force after forced lubrication was significantly lower than that before pressurization under three BHF conditions. When BHF was $20 \mathrm{kN}$, the force after forced lubrication of $5 \mathrm{MPa}$ and $9 \mathrm{MPa}$ was reduced by $8.0 \%$ and $8.6 \%$ respectively; when $\mathrm{BHF}$ was $35 \mathrm{kN}$, the force after forced lubrication of $5 \mathrm{MPa}$ and $9 \mathrm{MPa}$ was reduced by $2.4 \%$ and $3.5 \%$ respectively; When $\mathrm{BHF}$ was $50 \mathrm{kN}$, the force after forced lubrication of $5 \mathrm{MPa}$ and $9 \mathrm{MPa}$ was reduced by $3.4 \%$ and $8.9 \%$ respectively. After forced lubrication under 
$20 \mathrm{kN}$ and $50 \mathrm{kN}$ BHF, forming load decreases greatly, up to $8.9 \%$, which verified that the worse the friction conditions, the more effective the forced lubrication process was.

\subsection{Effect of lubrication conditions on wall thickness}

During sheet forming, the most direct impact of harmful friction in the flange area is to impede the flow of material to the center of die, increasing radial tensile stress in the sheet, thus increasing the forming load and leading to thickness thinning or even fracture. Hence, it is meaningful to improve the lubrication condition of die and sheet to delay fracture and inhibit thinning. From the analysis in the above section, it can be realized that too little BHF was easy to wrinkle, and material flow was difficult under too large BHF, which caused sheet metal to break prematurely. The most direct reason for fracture of sheet metal is excessive thinning, the moment of forming limit is the time when the material bears the maximum thinning rate. Therefore, it is not appropriate to evaluate lubrication effect adopting the wall thickness distribution at the maximum forming height of the part. It is more objective to evaluate lubrication effect by considering the wall thickness distribution of formed parts under the same BHF, the same forming height and different lubrication conditions. In this chapter, the thickness distribution of the part at a forming height of $35 \mathrm{~mm}$ under $35 \mathrm{kN}$ BHF was discussed. In order to explore the influence of different lubrication conditions on the variation trend of wall thickness of formed parts, the formed parts were cut along the center line of fillet area and straight edge area of box parts by wire cutting, and the wall thickness was measured as a measuring point at an interval of about 3-5mm along the cross section. The results are presented in Fig. 10. 

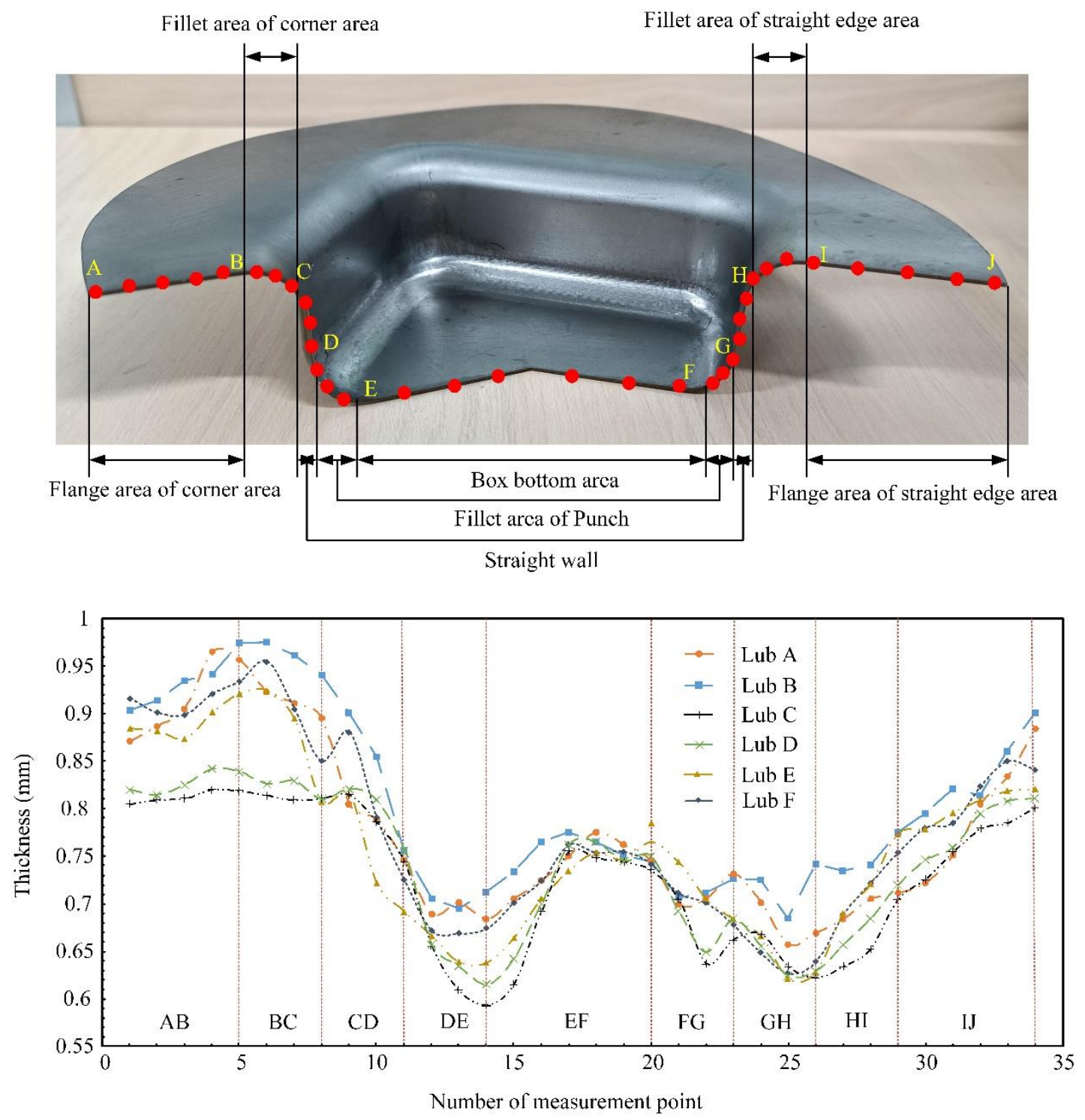

Fig. 10 Thickness distribution under different lubrication conditions

During sheet deep drawing process, the material in flange area is subjected to radial tensile stress and tangential compressive stress, which produces elongated and compressed deformation in radial and tangential directions, respectively. The thickness of the box part flange area near the die fillet area increases greatly, differing from the axially symmetrical parts in the outermost edge of the maximum thickness. According to Fig. 10, the degree of thickening in the flange area under the lubrication conditions of vegetable oil and mineral oil was not obvious, which indicated that there was less material flow in the flange area and a large part of the box-shaped part forming was completed by sheet thinning and stretching. The greater the thickening degree of the flange area, the more sufficient the plastic deformation was, as well as 
reflecting the more superior lubrication condition. The maximum degree of thickening using molybdenum disulfide lubrication reached $20.8 \%$, and the maximum degree of thickening at $5 \mathrm{MPa}$ and $9 \mathrm{MPa}$ forced lubrication increased by $9.4 \%$ and $10.9 \%$, respectively, compared with that without pressure. In the fillet area of die, the sheet was still thickened under tangential compressive stress in the fillet area of the box part corner area, while the thickness of sheet was thinned by tensile deformation and plastic bending in the fillet area of straight edge area. The straight wall area of the formed part is the force transmission area, which is subject to axial tension. The greater material flow resistance in the flange area will increase the tensile stress and thinner thickness in the force transmission area. The worse the lubrication effect, the more serious the thinning. From the above chart can be seen the wall thickness in straight wall area after the pressure lubrication was greater than ordinary lubricant lubrication. In addition, the thickness variation at each part of the cylinder wall area was uneven, and the closer to the bottom, the more serious the thinning of the plate material. The fillet area of the punch at the bottom of the box was the most dangerous area of the whole formed part, with the most serious thinning. The maximum thinning rates of molybdenum disulfide with the best lubrication condition and vegetable oil with the worst lubrication condition were $10.9 \%$ and $24.0 \%$ respectively. The maximum thinning rate of mineral oil and 5MPa-FLDD, 9MPa-FLDD were 21.2\%, $18.2 \%$ and $14.2 \%$, respectively. Obviously, forced lubrication played a suppressive role in the thinning, and the maximum thinning rate was reduced by a maximum of $7 \%$. The material at the bottom of box part had a very slow growth of radial tensile stress due to the friction between the punch and sheet, so the thickness of bottom center area changed less.

\section{Conclusion}

In the sheet forming process, in order to reduce the adverse effect of the friction in the flange area on the material forming and die wear, liquid or solid lubricating medium is usually applied to the sheet surface before forming. Nevertheless, traditional liquid lubricants are difficult to form and maintain under high contact pressure, meanwhile solid lubricant brings inconvenience to the forming accuracy, 
production environment and automatic production. To address this problem, a forced lubrication process employing an external pressure oil source for sheet metal forming was proposed in this paper. A series of experimental explorations were conducted, leading to the following conclusions.

(1) A forced lubrication drawing process was proposed for the lubrication problem in the flange area during deep drawing, process principle was elaborated die structure and hydraulic system were designed, and the feasibility of scheme was verified by deep drawing test.

(2) PE film, molybdenum disulfide, vegetable oil, and water-based mineral were selected for the horizontal comparison drawing test comparing with forced lubrication to evaluate the lubrication effect from the indexes of forming height, forming force and wall thickness distribution of the parts. The experimental results demonstrated that high purity molybdenum disulfide particles had the best lubrication effect, vegetable oil was the worst, the lubrication effect of water-based mineral lubricating oil was significantly improved after pressurization to $5 \mathrm{MPa}$ and $9 \mathrm{MPa}$, the maximum forming height was increased by $17.97 \%$, the maximum forming force was reduced by $8.9 \%$, the maximum wall thickness thinning rate was reduced by $7 \%$, and the lubrication effect of 9MPa pressure was better than $5 \mathrm{MPa}$.

(3) Comparison test indicated that there is still a certain disparity in lubrication effect between forced lubrication under the pressure of $5 \mathrm{MPa}$ and $9 \mathrm{Mpa}$ and the special lubrication media such as high-purity molybdenum disulfide. Yet, non-polluting vegetable oil, water can be selected for lubrication purposes in this process, which can be controlled qualitatively and quantitatively by adjusting the pressure and flow rate. PLDD process has definite advantages in improving the production environment, pollution control, and automated production.

Acknowledgements The authors would like to thank the forging and packaging experiment teachers of Yanshan University for their great help and suggestions in the process test.

Author contributions Methodology: Duan Chen, Changcai Zhao; experimental work: Duan Chen, Haoyang Li, Xiaoyi Chen; data analysis: Duan Chen and Haoyang Li; 
writing and editing: Duan Chen and Changcai Zhao. All authors have read and agreed to the published version of the manuscript.

Data availability All data calculated or analyzed during this research are included in this article.

Funding No funding was received to assist with the research of this manuscript.

\section{Declarations}

Competing interests The authors declare no competing interests.

\section{Reference}

1. Manikandan G, Verma RK, Biswas P (2015) Effect of friction in stretch forming and its influence on the forming limit curve. Proc Inst Mech Eng Part B-J Eng Manuf 229(6):973-981

2. Trzepiecinski T, Fejkiel R (2017) On the influence of deformation of deep drawing quality steel sheet on surface topography and friction. Tribol Int 115:78-88

3. Liu ZY, Xiong BQ, Li XW, Yan LZ, Li ZH, Zhang YG, Liu HW (2020) Effect of friction coefficient on deep drawing of 6A16 aluminum alloy for automobile body. $\mathrm{J}$ Wuhan Univ Technol-Mat Sci Edit 35(1):208-214

4. Uda K, Azushima A, Yanagida A (2016) Development of new lubricants for hot stamping of Al-coated 22MnB5 steel. J Mater Process Technol 228:112-116

5. Tan CJ, Aslian A, Abe Y, Mori K (2016) Improved seizure resistance of ultra-high-strength steel ironed cups with a lubricant containing $\mathrm{SiO}_{2}$ nanoparticles. Int J Adv Manuf Technol 87(5-8):1705-1711

6. Tan CJ, Ibrahim MS, Muhamad MR (2019) Preventing delayed cracks in SUS304 deep drawn cups using extreme blank holding forces aided by nanolubrication. Int $\mathbf{J}$ Adv Manuf Technol 100(5-8):1341-1354

7. Diabb J, Rodriguez CA, Mamidi N, Sandoval JA, Taha-Tijerina J, Martinez-Romero O, Elias-Zuniga A (2017) Study of lubrication and wear in single point incremental sheet forming (SPIF) process using vegetable oil nanolubricants. Wear 376:777-785.

8. Kamali H, Xie HB, Jia FH, Wu H, Zhao HY, Zhang HM, Li N, Jiang ZY (2019). 
Effects of nano-particle lubrication on micro deep drawing of $\mathrm{Mg}-\mathrm{Li}$ alloy. Int J Adv Manuf Technol 104(9-12):4409-4419

9. Wang CJ, Guo B, Shan DB, Bai XM (2013) Experimental research on micro-deep drawing processes of pure gold thin sheet using DLC-coated female die. Int J Adv Manuf Technol 67(9-12):2477-2487

10. Hu ZY, Schubnov A, Vollertsen F (2012) Tribological behaviour of DLC-films and their application in micro deep drawing. J Mater Process Technol 212(3):647-652 11. Wang CJ, Wang CJ, Guo B, Shan DB (2014) Effects of tribological behavior of DLC film on micro-deep drawing processes. Trans Nonferrous Met Soc China 24(9):2877-2882

12. Wang CJ, Cheng LD, Liu Y, Zhang H, Wang Y, Shan DB, Guo B (2019) Research on micro-deep drawing process of concial part with ultra-thin copper foil using multi-layered DLC film-coated die. Int J Adv Manuf Technol 100(1-4):569-575

13. Sulaiman MH, Farahana RN, Bienk K, Nielsen CV, Bay N (2019) Effects of DLC/TiAlN-coated die on friction and wear in sheet-metal forming under dry and oil-lubricated conditions: Experimental and numerical studies. Wear 438-439

14. Chen P, Shi Z, La YQ, Xiang X (2018) Stamping simulation analysis based on tribological properties of die-binder area. China Surface Engineering 31(1):59-66(in Chinese)

15. Chen P, Liu XJ, Huang MJ, Shi Z, Shan B, Huang M (2018) Numerical simulation and experimental study on tribological properties of stamping die with triangular texture. Tribol Int 132:244-252

16. Taha-Tijerina JJ, Garza G, Maldonado-Cortes D (2018) Evaluation of parameters for application of Laser Surface Texturing (LST) in tooling for the sheet-metal forming process. Ind Lubr Tribol 70(4):620-627

17. Lang LH, Danckert J, Nielsen KB (2004) Investigation into hydrodynamic deep drawing assisted by radial pressure: Part I. Experimental observations of the forming process of aluminum alloy. J Mater Process Technol 148(1):119-131

18. Hama T, Kurisu K, Matsushima K, Fujimoto H, Takuda H (2009) Outflow characteristics of a pressure medium during sheet hydroforming. ISIJ Int 
49(2):239-246

19. Abbadeni M, Zidane I, Zahloul H, Fatu A, Hajjam M (2017) Finite element analysis of fluid-structure interaction in the hydromechanical deep drawing process. $\mathbf{J}$ Mech Sci Technol 31(11):5485-5491

20. Horikoshi Y, Kuboki T, Murata M, Matsui K, Tsubokura M (2015) Die design for deep drawing with high-pressured water jet utilizing computer fluid dynamics based on Reynolds' equation. J Mater Process Technol 218:99-106

21. Yang TS (1999) Full film lubrication of deep drawing. Tribol Int 32(2):89-96

22. Yang TS (2010) Investigation of the strain distribution with lubrication during the deep drawing process. Tribol Int 43(5-6):1104-1112

23. Fukui S, Yoshida K (1954) The scale effects on deep-drawing of circular shells. Report of Science and Technology Institute.University of Tokyo 8:23-30

24. Rivas-Menchi A, Medellin-Castillo HI, de Lange DF, Garcia-Zugasti PD (2018) Performance evaluation of analytical expressions for cylindrical and rectangular deep drawing force estimation. J Manuf Process 36:340-350 